\title{
Methodological Issues in Ethnic and Racial Identity Research With Ethnic Minority Populations: Theoretical Precision, Measurement Issues, and Research Designs
}

\author{
Seth J. Schwartz \\ University of Miami \\ Tiffany Yip \\ Fordham University \\ Deborah Rivas-Drake \\ Brown University
}

\author{
Moin Syed \\ University of Minnesota
}

George P. Knight and

Adriana J. Umaña-Taylor

Arizona State University

Richard M. Lee

University of Minnesota

Ethnic and Racial Identity in the 21st Century Study Group

\begin{abstract}
This article takes stock of research methods employed in the study of racial and ethnic identity with ethnic minority populations. The article is presented in three parts. The first section reviews theories, conceptualizations, and measurement of ethnic and racial identity (ERI) development. The second section reviews theories, conceptualizations, and measurement of ERI content. The final section reviews key methodological and analytic principles that are important to consider for both ERI development and content. The article concludes with suggestions for future research addressing key methodological limitations when studying ERI.
\end{abstract}

The widespread study of ethnic and racial identity (ERI) has been ongoing for more than two decades. A cursory search of the PsycInfo literature base from 1990 to 2012 yielded 632 records with "ethnic identity" in the title and 395 additional records with "racial identity" in the title. These numbers indicate that more than 1,000 journal articles were published on ERI in a 22-year span. Although a number of review articles have been written about the course and content of ERI research (e.g., Cokley, 2007; Umaña-Taylor, 2011), our intention in this

Deborah Rivas-Drake is now at the University of Michigan.

This article was prepared as part of the Ethnic and Racial Identity in the 21st Century working group. Group members not listed on the author byline include William E. Cross Jr., Sabine E. French, Carol A. Markstrom, Stephen M. Quintana, Eleanor K. Seaton, and Robert M. Sellers. The authors gratefully acknowledge the funding for this working group provided by the Society for Research in Child Development, Society for Research on Adolescence, APA Division 45, the Center for the Study of Ethnicity and Race in America and the Center for the Study of Human Development at Brown University, and the T. Denny Sanford School of Social and Family Dynamics at Arizona State University.

Correspondence concerning this article should be addressed to Seth J. Schwartz, Department of Public Health Sciences, Leonard M. Miller School of Medicine, University of Miami, 1425 N.W. 10th Avenue, Suite 321, Miami, FL 33136. Electronic mail may be sent to sschwartz@med.miami.edu. article is to focus specifically on methodological issues in studying ERI from a developmental perspective. The methodological issues that we cover here go beyond measurement concerns, which have been reviewed by Phinney and Ong (2007), to include issues of research design, measurement equivalence, and analytic approaches that may be uniquely matched to specific research questions that can help to move the field forward.

This review is structured into three major sections. We begin with the issue of overlap versus independence between ethnic and racial identity. This issue is of critical importance because the literatures on ERI developed largely separately from one another, and integrating them into a superordinate construct requires an examination of areas of potential overlap versus independence between them. The second section presents a brief overview of the major theoretical models, concepts, and measures focusing on ERI development over time. Readers

(C) 2013 The Authors

Child Development (C) 2013 Society for Research in Child Development, Inc. All rights reserved. 0009-3920/2014/8501-0005

DOI: $10.1111 /$ cdev.12201 
should consult Umaña-Taylor, Quintana, et al. (in press) for an in-depth conceptual discussion of ethnic identity and racial identity. In the second section, we review key theories, concepts, and measures related to ethnic or racial identity content. Finally, we discuss what we believe are the primary methodological and analytic considerations for the ethnic or racial identity literature.

\section{Ethnic Identity and Racial Identity: Overlapping or Distinct?}

We define both ethnic and racial identity as a subjective, self-ascribed sense of oneself as a member of an ethnic or racial group - rather than in terms of the label that one assigns to the group itself. Concerning the ways in which ethnic and racial identity might be invoked in different situations, Cokley (2007, p. 225) offers the following guidance:

When researchers are interested in how individuals see themselves relative to their cultural beliefs, values, and behaviors, ethnic identity is the more appropriate construct to study ... however, when researchers are more interested in how individuals construct their identities in response to an oppressive and highly racialized society, racial identity is the more appropriate construct to study.

It may be possible to distinguish conceptually between ethnic and racial identity as part of academic discourse. However, in daily life, particularly in the United States, ERI are often functionally equivalent. In this article, we adopt an integrative perspective, where ERI are distinct in some ways and overlap in other ways. Clarifying these areas of difference and convergence is essential if we are to develop an understanding of how race and ethnicity contribute to the development of self-understanding and self-categorization.

We begin with ways in which ethnic and racial identity may be distinct from one another. Although Cokley (2007) argues that ethnic identity is often used as a "euphemism" for racial identity, others have designated ethnic and racial identity as different from one another, both theoretically (Helms \& Cook, 1999) and empirically (Worrell \& Gardner-Kitt, 2006). Phinney (1996) specifies the referent for ethnic identity as a group with a shared set of values and norms, and specifies the referent for racial identity as a group with a specific skin tone. However, this distinction is less relevant for some groups than for others. For example, given the history of African Americans in the United States, Sellers and colleagues (e.g., Yip, Seaton, \& Sellers, 2010) often use measures of ethnic identity to index racial identity - with the assumption that race and ethnicity are inseparable for African Americans. Indeed, the social realities of African Americans are shaped by a legacy of slavery and by continued experiences of social devaluation (Gaskin, Headen, \& White-Means, 2005). Largely due to unequal opportunities and discriminatory social dynamics, African Americans are most likely to be incarcerated (Crutchfield, Fernandes, \& Martinez, 2010) and to be misdiagnosed by physicians (Moskowitz, Stone, \& Childs, 2012), among other negative outcomes. Although members of other ethnic minority groups (e.g., Latinos, Asians) may not have the same specific social experiences (e.g., history of U.S. slavery), they have other social experiences (e.g., antiimmigrant sentiment; English-only policies) that are similarly discriminatory (see Umaña-Taylor, Quintana, et al., in press). It is therefore not clear for whom "race" and "ethnicity" carry the same (or similar) meanings, and for whom they do not.

Ethnic and racial identity also are both claimed by individuals with different heritages, skin tones, family socialization experiences, and so on-suggesting a large degree of heterogeneity in the specific meaning of ethnic and racial identity both within and across specific ethnic and racial groups. Ethnicity and race may be highly salient to some individuals but less salient to others. Furthermore, through a process of intersectionality, ethnic and racial identity will likely interact with other identity categories to determine a given person's unique identity profile-for example, being an African American woman is likely more than just a linear combination of African American and female identities (Bowleg, 2008).

As noted by Umaña-Taylor, Quintana, et al. (in press), it is possible that the conceptualization and use of a metaconstruct (i.e., ethnic-racial identity; ERI) may be necessary for understanding and measuring experiences that are not uniquely ethnic or racial, and that inform one's identity as a member of a particular ethnic or racial group. Ethnic and racial identity both draw upon the person's conception of herself or himself as a member of a social group, and as such, both of these identity dimensions imply claiming membership in the group and placing some degree of positive or negative affect onto it (Ashmore, Deaux, \& McLaughlin-Volpe, 2004). Accordingly, we primarily refer to ERI, although we sometimes use racial identity and ethnic identity when describing models that make reference to only one or the other. 


\section{Developmental Models of Ethnic and Racial Identity}

Developmental models focus primarily on the process of ERI development-the psychological experience of developing an identity (Phinney, 1990). The primary focus in this case is how ERI develops over time. Developmental models typically trace the genesis and evolution of ERI during childhood, adolescence, and adulthood. Although not all of these models are explicit regarding the specific age periods to which they refer, this information can often be inferred from the competencies that are assumed to operate within each theory. For example, perspectives that include exploring the subjective meaning of one's ethnic group membership refer, by definition, to adolescence and adulthood; younger children do not possess the necessary cognitive skills to engage in the counterfactual thinking that exploration requires (Krettenauer, 2005).

We review two prominent developmental models of ERI introduced by Phinney (1990) and by Cross (1991). Phinney's model builds upon Erikson's (1950) stages of psychosocial development and identity status theory (Kroger \& Marcia, 2011), and it provides a universal template for studying ERI across racial/ethnic groups. Her model and its accompanying measures, including the Multi-group Ethnic Identity Measure (MEIM; Phinney, 1992; Phinney \& Ong, 2007), focus almost entirely on the processes underlying ethnic identity development. By contrast, Cross's model was developed specifically to index the African American experience (Cross \& Strauss, 1998; Helms, 1990). His model and its accompanying measures, including the Cross Racial Identity Scale (CRIS; Vandiver, Cross, Worrell, \& Fhagen-Smith, 2002), focus on the content of specific stages of racial identity development. We briefly review these two approaches, attending particularly to measurement approaches and methodological assumptions.

\section{Phinney's Universal Model of Ethnic Identity}

The study of ethnic identity has been dominated by studies of adolescent and emerging adult participants, grounded in Phinney's approach and using the MEIM. Phinney's conceptualization of ethnic identity integrates the exploration and commitment dimensions from Marcia's (1966) identity status model with the affirmation dimension from social identity theory (Tajfel \& Turner, 1986). Individuals are assumed to proceed from a state of being unconcerned with or unaware of ethnicity (diffusion), to a state of active exploration of the meaning of one's ethnicity (moratorium), and finally to a resolution of what the person's ethnicity means to her or him (achievement). Along with achievement comes affirmation - a positive attachment to one's ethnic group and to others who belong to that group.

The MEIM has been the most frequently used ethnic identity instrument (Phinney \& Ong, 2007). Phinney (1992) originally identified three subscales within the MEIM: affirmation/belonging, achievement, and ethnic behaviors. Later, Phinney and colleagues (Roberts et al., 1999) adopted a two-factor structure (exploration and commitment) for the MEIM, making it more theoretically consistent with Marcia's (1966) identity status model. Many other studies using the MEIM have created a composite score by summing responses to the exploration, commitment, and affirmation items (e.g., Bracey, Bámaca, \& Umaña-Taylor, 2004), and still others have used only selected items (e.g., Huang \& Stormshak, 2011). Furthermore, the exploration and commitment subscales tend to be highly correlated. For instance, Phinney and Ong (2007) found a correlation of .74 between factors representing the two subscales. Cokley (2007) notes that because of this high correlation and the resulting ambiguity in the MEIM's factor structure, different researchers use different scoring algorithms for the measurewhich likely increases confusion regarding precisely what is being measured. This issue is important, as research indicates that exploration and commitment follow different developmental courses (Pahl \& Way, 2006) and are differentially related to psychological outcomes (Lee \& Yoo, 2004). Indeed, it is vitally important that the measures being used are matched with the constructs specified within one's theoretical perspective. What is problematic is not necessarily the use of the MEIM in and of itself, but rather the uncritical use of the measure without ensuring that it is properly matched with the research questions being asked.

Some conceptual revisions have been made to Phinney's model in the years since it was introduced. Principally, whereas Phinney considered commitment and affirmation to be part of the same process, Umaña-Taylor, Yazedjian, and BámacaGómez (2004) unpacked commitment into two separate processes-affirmation and resolution. As described by Umaña-Taylor et al., affirmation refers to feelings of solidarity with and positive affect toward a social group. In turn, social identity theory (Tajfel \& Turner, 1986) hypothesizes this solidarity 
and positive affect as leading to increases in wellbeing. Resolution refers to a personal sense of commitment to a specific view of one's ethnicity-such that the person is comfortable with the subjective significance of her or his ethnic group. UmañaTaylor et al. designed the Ethnic Identity Scale (EIS) to measure exploration, affirmation, and resolution separately. Research on the EIS has been promising so far (Umaña-Taylor et al., 2004; Yoon, 2011).

\section{Nigrescence Theory-A Group-Specific Approach to Racial Identity Development in African Americans}

Group-specific developmental models have tended to focus on racial identity, largely among African Americans. Nigrescence theory (Cross, 1991; Parham \& Helms, 1985) and its derivatives, such as racial identity theory (Helms \& Cook, 1999), outline a progression of stages beginning from unawareness of racial issues and proceeding toward integration of race-related issues within one's identity. Although they adopt a developmental perspective, the Cross and Helms models are not rooted in Erikson's theory and therefore are not explicitly associated with adolescence and emerging adulthood. Instead, Cross's and Helms's models refer to the entire life span and allow for individuals to revisit other developmental stages (later revised as statuses). Specifically, the preencounter stage refers to adopting a White or European American worldview that devalues Blackness and idealizes Whiteness. The encounter state refers to abandoning this pro-Whiteness view in response to specific life events such as discrimination. The immersion-emersion stage reflects an idealization of Blackness and a denigration of Whites, as well as more active involvement in Black experiences. Internalization refers to the achievement of a feeling of inner security with one's Blackness and the incorporation of Blackness into one's self-concept.

This CRIS, which is the most commonly used nigrescence measure, consists of multiple subscales for three of the four hypothesized racial identity stages. For example, three subscales correspond to the pre-encounter stage (Pre-Encounter Assimilation, Pre-Encounter Miseducation, and Pre-Encounter Self-Hatred) and two subscales correspond to the internalization stage (Internalization-Afrocentric and Internalization Multiculturalist Inclusive; Vandiver et al., 2002). Interestingly, no scale was developed for the encounter stage; Cross (1991) posits that encounter is not so much a stage or status of identity as it is a process of reexamination of one's reference group orientation in response to life events.

\section{The Multidimensional Model of Racial Identity: A Content-Focused Model of ERI}

Sellers, Smith, Shelton, Rowley, and Chavous (1998) proposed a nondevelopmental approach to the study of ERI. Rather than outlining a developmental sequence, this Multidimensional Model of Racial Identity (MMRI) approach focuses on the significance and meaning (content) of race for African Americans in their daily life. In particular, Sellers et al.'s model identifies four dimensions of racial identity: salience, centrality, regard, and ideology. Salience indexes the importance of racial identity in specific situations, such as experiences of discrimination, whereas centrality refers to the extent to which race is important to an individual in a more characteristic or trait-like way. Centrality interacts with characteristics of a specific situation to produce feelings of salience-although salience can sometimes emerge from experiences of discrimination or hostility even among people for whom ethnicity or race is not central (Rumbaut, 2008). The regard dimension is further divided into public and private components, where public regard refers to the ways in which an individual believes that others view her or his racial group, and private regard refers to one's feelings about one's own racial group membership. The ideology dimension is divided into nationalism, oppressed minority, assimilationist, and humanist beliefs. Nationalism refers to a belief that African Americans share a unique cultural and historical experience. Oppressed minority attitudes refer to beliefs that African Americans share similarities with other minority groups. Assimilationist attitudes refer to beliefs that African Americans share commonalities with other Americans. Finally, humanist beliefs highlight the commonality that African Americans share with humanity as a whole.

The MMRI has been operationalized using the Multidimensional Inventory of Black Identity (MIBI; Sellers, Rowley, Chavous, Shelton, \& Smith, 1997), which includes an adolescent version (Scottham, Sellers, \& Nguyen, 2008). Although the MMRI and MIBI were originally developed to assess the ERI development of African Americans, the model and measure have been adopted for other racial-ethnic groups, including Asian Americans and Latinos (Rivas-Drake, Hughes, \& Way, 2009; Yip, 2005). The MIBI specifically measures centrality, ideology, and regard, but does not include a measure of salience (which refers to specific life events). The MIBI also draws upon Luhtanen and Crocker's (1992) model and measurement of collective self-esteem to 
assess private and public regard. The MIBI also has four ideology subscales (Nationalist, Oppressed Minority, Assimilationist, Humanist) that, to an extent, conceptually mirror some of the identity stages articulated by nigrescence theory (Cross, 1991). Since its introduction, the MIBI has become the second most commonly used ERI measure, following the MEIM. Most research using the MIBI across racial/ethnic groups has typically used only the centrality and regard (private and public) subscales (e.g., Casey-Cannon, Coleman, Knudtson, \& Velazquez, 2011; Johnson, Kurpius, Rayle, Arredondo, \& Tovar-Gamero, 2005), given that the ideology subscales are tailored more specifically to the African American experience.

\section{Outstanding Conceptual and Methodological Issues in the ERI Literature}

As reviewed above, the ERI literature includes two philosophically-and thus methodologically-different approaches. Stemming from these core philosophical and methodological differences, there are a number of related methodological debates within the ERI literature. We review here what we believe are the three most pressing of these issues. First, to what extent should ERI models focus on the processes (mechanisms, such as exploration and commitment) through which ethnic or racial identity develops, and to what extent should ERI models focus on the specific content (characteristics, such as centrality and valence) of the identity being developed? Second, to what extent are developmental processes and related content universal versus group-specific? For example, which is a better fit to the ERI landscape-Phinney's and Umaña-Taylor's models, where a single theoretical understanding of ethnic identity can be used across groups, or the Cross, Helms, and Sellers models, which were originally developed to capture the experiences of a specific group? Finally, although many ERI models are developmental, these models are inconsistent in terms of the age periods studied. Most studies have focused on adolescence and emerging adulthood, with far less attention to childhood and adulthood.

\section{Process and Content in ERI}

The MEIM and EIS were designed primarily to index ethnic identity processes, the CRIS was developed to assess racial identity processes, and the MIBI was designed primarily to index racial (and in some adaptations, ethnic) identity content. How- ever, process and content cannot be so neatly separated. If a person's race or ethnicity is especially central to her sense of self, then can we assume that this person is committed to a specific view of her race or ethnicity? Similarly, if a person has not explored the subjective meaning of, and is not committed to a specific view of, her race or ethnicity, then can we assume that she is low on centrality? Although identity status approaches do not attend explicitly to the content of the identity being developed, the very act of exploring potential identity configurations in a given content domain-such as ethnicity-suggests that the identity that is eventually developed will be regarded as central and important. The amount of effort and psychological resources that identity exploration requires (Schwartz, Zamboanga, Weisskirch, \& Rodriguez, 2009) indicates that individuals are unlikely to invest such effort and resources into domains that they do not consider important.

An important first step in integrating process and content is to examine the ways in which existing ERI measures have aimed to focus on process and content. The MEIM and the EIS both include items that capture process (exploration, resolution, commitment) and content (affirmation), such that it may be unclear whether these measures are intended to assess process, content, or both. However, much of the work in which these measures have been used focuses on the process of ethnic identity formation-likely a consequence of the conceptual grounding of these measures in Erikson's (1968) theory and Marcia's (1966) identity status approach. Consequently, studies using the MEIM have typically conceptualized ERI as defined by exploration and commitment, with the assumption that a strong commitment would carry a positive valence (i.e., high affirmation). In more recent work, however, affirmation (content) has been examined separately from exploration and resolution (e.g., Lee, 2005; Umaña-Taylor, Gonzales-Backen, \& Guimond, 2009). Indeed, empirical work suggests it is possible for a person to be committed to a negative view of her or his ethnic or racial group (Umaña-Taylor et al., 2004).

There are at least two ways to facilitate a greater understanding of the interplay between process and content in ethnic/racial identity. One way is to develop new measures that clearly tap into both process and content. Another way, using existing measures, is to draw upon the inclusion of process and content to varying extents within different ERI measures. Innovative combinations of existing ERI instruments can lead to new and interesting 
research questions. For example, Yip, Seaton, and Sellers (2006) found that African Americans with an achieved sense of ethnic identity scored higher on racial centrality and private regard compared to those with a diffused sense of ethnic identity. This finding supports the proposition that exploring and committing to a sense of racial/ethnic identity increases the likelihood that this identity will be considered positive and central. For another example, integrating survey-based and narrative approaches, Syed and Azmitia (2008, 2010) found that when asked about an experience that first made them aware of their race or ethnicity, individuals higher in ethnic identity exploration were most likely to recount experiences of discrimination or of connecting to their cultural backgrounds. This integration of process and content provides insight into "what it is like" to identify with one's ethnic group, and thus goes beyond simple descriptions of "strength" of one's ethnic identity.

In sum, the integration of primarily processbased approaches with primarily content-based approaches can provide a richer, more nuanced understanding of the ways in which individuals are considering the role of race and ethnicity within their overall sense of self, while at the same time negotiating the significance and meaning of that identity across situations. Importantly, this new line of research has come about through methodological innovations, which have subsequently led to new questions that had not previously been considered.

\section{Ethnic and Racial Groups: Universal Versus Group-Specific Models}

Ethnic and racial groups are collective entities that confer specific identities on their members, while at the same time permitting their members to identify with the group to varying extents (Ashmore et al., 2004). An individual is simultaneously a unique person and a member of any number of social groups (Brewer, 2003). In some situations, personal identity may be most salient, such that one's individual goals and beliefs guide one's decisions and behaviors. However, in other situations, such as when one witnesses or experiences discriminatory acts against one's ethnic or racial group, group identity becomes most salient, and one's decisions and behaviors are guided more strongly by the perceived needs and desires of the group (see Spears, 2011, for a comprehensive review).

From an intergroup perspective, ERI might be viewed as resulting from the tendency to self-categorize into groups when a group to which one belongs is unfavorably compared to other relevant groups (Turner, Hogg, Oakes, Reicher, \& Wetherell, 1987). "Identity management" strategies are used to reframe one's group membership positively rather than negatively (Mummendey, Klink, Mielke, Wenzel, \& Blanz, 1999) — for example, some African Americans may focus on superior athletic prowess or musical ability rather than on other domains in which they are perceived as inferior. ERI is essentially an identity management strategy where group membership is cast (in most cases) as a positive attribute.

Groups have collective histories that influence what it means to identify with the group. For example, the collective history of African Americans involves slavery, indentured servitude, and formal and informal discrimination and oppression. In contrast, the group called "Latinos" is the product of individuals from many different countries being grouped together in the United States because of their shared linguistic heritage. To what extent are the processes and contents of ERI comparable across these two groups? This tension between group-specific models, where each group is considered to have its own unique identity concerns, and generalizable models, where ERI is considered to operate similarly across groups, remains a key unresolved issue in the study of ERI. As we will argue next, the resolution to this issue may not be a "whether or not" answer, but rather a "how much of each" answer.

In her landmark review of ethnic identity research, Phinney (1990) described the field as consisting of studies focusing on individual ethnic groups, often using measures designed for those groups only (e.g., nigrescence theory; Cross, 1991). This fragmentation, she suggested, was one of the barriers to the advancement of research on ERI, as there was no common language, set of definitions, or measurement tools that could support a cumulative knowledge base. Importantly, Phinney suggested that the processes underlying ERI were similar across various ethnic groups, and thus the MEIM was ethnic general, in that it was not specific to the culture of any one ethnic group. This ethnic generality has facilitated comparative ERI research across different ethnic groups (Pahl \& Way, 2006; Roberts et al., 1999; Syed \& Azmitia, 2009) and has contributed greatly to the popularity of this instrument.

Partially in response to the proliferation of universal approaches to ERI, Sellers et al. (1998) developed the MMRI, which was intended to specifically explicate the contents and functions of racial identity among African Americans. The MMRI and the 
MIBI return to a focus on theory and measures targeted for specific groups. However, although the MMRI collectively reflects a group-specific approach, most of the model's individual dimensions are drawn from collective identity concepts that can be applied to multiple groups. Indeed, only the Ideology component is grounded in uniquely African American themes identified in pertinent literature, art, political issues, and historical dilemmas.

Although the development of ethnic-specific models and measures may be appealing, they are not without their pitfalls. One major issue is determining the specificity of an ethnic-specific model. "Ethnic groups" are difficult to define and can be understood at multiple levels (Gjerde \& Onishi, 2000). For example, some researchers study ERI within Asian Americans (Lee \& Yoo, 2004), whereas others study individual Asian-heritage subgroups, such as Korean Americans (Lee, 2005) and Chinese Americans (Yip, 2005). Similar issues arise in the context of studying ERI among Latinos (see Way, Santos, Niwa, \& Kim-Gervey, 2008), where it is not clear exactly who is-and who is not-included under the heading of "Latino." Complex migration histories also can complicate the measurement of ethnic/racial identity. For example, a child of Korean immigrant parents who was born in Ecuador and then immigrates to the United States as an adolescent may identify ethnically as both Korean and Ecuadorian due to shared cultural and linguistic experiences with both groups. A Vietnamese child adopted by White American parents likewise may identify as both Vietnamese and White given his upbringing in a White family. Thus, as researchers consider developing models and measures that are specific to ethnic groups, they must use great care in considering the boundaries of such groups.

Racial identity, by definition, may be difficult to study across groups using the same theories and measures. As a social construction, race is intertwined with the collective experiences of a given racial group - such as slavery and institutionalized discrimination for African Americans (Gaskin et al., 2005), the trauma associated with systematic killing or destruction of Native American people and their lands (Markstrom, 2011), the model minority myth among Asian Americans (Yoo, Burrola, \& Steger, 2010), and the perpetual foreigner treatment of Asian Americans and Latinos (Cheryan \& Monin, 2005). Segmented assimilation experiences (e.g., Portes, Fernández-Kelly, \& Haller, 2005) also challenge traditional models of racial identity. Immigrant youth who grow up in racially segregated, urban areas may identify more strongly with the dominant racial group (e.g., African Americans) in their immediate environment, including that group's culture and lifestyle, than with their own ethnic or racial groups.

Phenotype and national origin are sometimes, but not always, considered in the study of ERI. For Latinos, who can be of any race, phenotype is complicated by the typical U.S. racial categorizations-which are influenced by skin tone and heavily challenged biological theories of race (see Teo, 2009). Indeed, in the Census 2000 data collection, over $40 \%$ of Latinos selected "some other race" for their racial classification (Hitlin, Brown, \& Elder, 2007). The importance of phenotype goes beyond classification issues. López (2008), for example, found that skin color moderated the association between ethnic identity and self-esteem among a sample of mainland Puerto Rican women. Specifically, ethnic identity was more strongly predictive of self-esteem for lighter skinned women than for darker skinned women. This finding suggests that darker skinned women-who are likely more easily identifiable as Latino - are at a disadvantage even when they do identify with their cultural heritage. Similarly, in a study of Mexican American adolescents, higher levels of family ethnic socialization were associated with more positive feelings about ethnicity, but only for youth rated as having a more Latino appearance and darker skin (GonzalesBacken \& Umaña-Taylor, 2011). Latinos are not, however, the only group for which varying phenotypes and national origins can complicate the study of ERI. Many Caribbean and African Blacks are regarded as African Americans because of their phenotypic similarity, even though the cultural groups are quite different (Waters, 1999). In cases such as this, is ERI promotive of well-being and protective against internalizing symptoms, externalizing problems, and health risk behaviors? For a Caribbean Islander, does being mistaken for an African American offset the protective and promotive effects of ERI (Waldinger \& Feliciano, 2004)? How "Asian" must someone be to be eligible to participate in a study of Asian American ethnic identity? Must both parents be of Asian descent, or is it sufficient to have only one parent (or even one grandparent) with ancestry in an Asian country? These are some of the tough questions that psychological research on ERI needs to address.

In some cases, such as the Ideology component of the MMRI (Sellers et al., 1998), models of ERI may be designed for specific groups, and there may be no reason for examining such models or con- 
structs across groups. Given that theoretical models guide analytical decisions, and given that research results help to refine the theories on which the research is based (Greenwald, 2012), the decision regarding whether to sample from multiple ethnic, racial, or cultural groups in a given study should be guided by strong theorizing regarding the extent to which the ERI model in question is applicable across groups. In some cases, however, there may be a posteriori reasons for examining the consistency of models across groups. For example, Kao and Travis (2005) evaluated the adequacy and usefulness of a measure of filial piety - a traditionally East Asian value system emphasizing respect for parents, deference to authority, and saving face - in samples of Latinos. Although filial piety has been discussed as an Asian value system, results reported by Kao and Travis suggest that it may be syntonic with other cultural groups as well. We provide this example to illustrate that there may sometimes be reasons to sample from multiple groups even if a given model was designed with one specific group in mind.

So how can we resolve this debate between group-specific and universal models? How can we increase the theoretical precision of ERI research, which is facilitated by group-specific models, yet also retain the ability to compare across groups, which is facilitated by universal models? Although this issue has been present in the literature for many years, little research has addressed it directly. That is, for the most part, researchers appear to choose one approach or the other rather than engaging the debate. However, integrating universal and groupspecific approaches is necessary to support expansive research syntheses and the development of a strong cumulative knowledge base. It may be useful for future research to explicitly explore common and unique elements of ERI across groups. That is, there are likely aspects of ERI that are both ethnic general (e.g., exploration) and ethnic specific (e.g., ideology). Next, we provide some methodological approaches for addressing this issue.

\section{Factor Analysis as a Methodological Tool in ERI Research}

Despite the appeal of universal models of ERI, the majority of ERI studies have sampled from a single ethnic group (e.g., Lee, Yoon, \& Liu-Tom, 2006; Pegg \& Plybon, 2005; Schwartz \& Zamboanga, 2008; Seaton, Yip, \& Sellers, 2009), whereas a smaller number of studies have examined multiple ethnic groups (e.g., Roberts et al., 1999; Syed \&
Azmitia, 2009). Even fewer studies have examined ERI across ethnic groups and conducted statistical analyses to examine the consistency of factor structures and structural associations across groups (Knight, Roosa, \& Umaña-Taylor, 2009). Such equivalence analyses can help to determine empirically the extent to which a specific model of ERI is applicable to multiple ethnic groups. Next we discuss two uses of factor analysis - determining the number of factors and invariance testing-that can be helpful to this end.

Factor structure. All existing measures of ERI are theoretically multidimensional. Accordingly, there is a need to provide evidence for this multidimensionality, both within and between groups. Despite its widespread use, the factor structure of the MEIM is not entirely clear and may depend on the version of the instrument used. In terms of version, all available evidence supports a two-factor (exploration and commitment) versus one-factor structure for the 12-item (Roberts et al., 1999) and 6-item (Phinney \& Ong, 2007; see Pegg \& Plybon, 2005; Syed \& Azmitia, 2009; Yoon, 2011) versions. The factor structure of the original 20-item version (Phinney, 1992), however, is less clear. As outlined by Worrell and Gardner-Kitt (2006), part of the problem has to do with the composition of the 20-item version. In actuality, the MEIM-20 contains two scales-14 items assessing exploration, commitment, affirmation, and ethnic behaviors, and a separate 6-item scale for other-group orientation. Some researchers have included the other-group attitudes scale in their factor analyses (e.g., Ponterotto, Gretchen, Utsey, Stracuzzi, \& Saya, 2003), whereas others have not (e.g., Lee \& Yoo, 2004). Two studies conducting factor analyses of the 14-item version have found three factors, corresponding to clarity/resolution, pride/ affirmation, and engagement/exploration (Juang, Nguyen, \& Lin, 2006; Lee \& Yoo, 2004). These are the same factors that the EIS measures (resolution, affirmation, and exploration; Umaña-Taylor et al., 2004; Yoon, 2011). The differences in factor structure seem attributable to whether affirmation and resolution are combined into a commitment scale (MEIM6, MEIM-12) or kept separate (MEIM-14, EIS). Importantly, the aforementioned analyses have been conducted with ethnically diverse samples, providing support for the argument that the structure of ERI, as measured by the MEIM and EIS, is robust across groups. However, extracting parallel factors for different groups across studies is not the same as empirically evaluating the equivalence of these factors. For that, one would need to conduct measurement invariance tests, to which we now turn. 
Invariance analyses: Determining structural similarity of ERI components across groups. Provided that data have been collected on multiple ethnic, racial, or cultural groups, an important step in testing the group specificity versus generalizability of ERI models is to conduct multigroup invariance analyses. These analyses are generally conducted on measurement models (i.e., confirmatory factor analysis models where latent variables are defined by their indicators and are allowed to correlate, but where no directional paths are included; Millsap \& Olivera-Aguilar, 2012). In a measurement model where each indicator is attached to only one latent factor, the regression model for predicting observed scores on a given indicator variable $X_{i}$ is presented as $X_{i}=\tau_{i}+\lambda_{i} \mu+\delta_{i}$, where $\tau$ represents the item intercept, $\lambda$ represents the factor loading (slope), $\mu$ represents the mean of the latent factor, and $\delta$ represents the error or residual term. All four of these parameters can be tested for invariance across groups. However, it is most common for researchers to test only factor loadings and item intercepts (Dimitrov, 2010).

Generally speaking, three levels of invariance are of primary interest to most researchers - configural invariance, metric/weak invariance, and scalar/ strong invariance. The invariance testing process moves from the least to the most restrictive models, with each successive model subsuming the previous one. The first test is for configural invariance, which involves estimating the same measurement model simultaneously on each of the groups included in analysis. That is, whether the same items load onto the same factors for each group tested (as described in the preceding section of the factor structure of the MEIM). The second test is for metric/weak invariance, which involves testing the assumption that the factor loadings for each indicator on its corresponding latent factor are equivalent across groups. Meeting this assumption permits group comparisons of correlations, covariances, or structural relations involving the constructs for which metric/weak invariance has been established. For example, if affirmation and resolution are both specified as latent factors and defined by the individual item responses included on each subscale, a finding of metric/weak invariance across ethnic-racial groups permits examination of the correlation between these factors within each group. The third step of the invariance testing process involves testing for scalar/strong invariance, which refers to the assumption that the item intercepts, or item means, are equivalent across groups. A finding of scalar/strong invariance permits the comparison of mean scores across groups.
Additional invariance tests that can be conducted, but are generally not viewed as required components of the invariance testing process, are strict invariance (equivalence of error/residual terms) and comparisons of latent means across groups (which are analogous to $t$ tests or analyses of variance, but are conducted on error-free latent variables).

Determining whether or not invariance has been established is dependent on both statistical and substantive criteria. The criteria for statistical fit indices, such as the chi-square goodness-of-fit test, the comparative fit index, and the root mean square error of approximation, have been a subject of considerable debate (Cheung \& Rensvold, 2002; Tomarken \& Waller, 2005; West, Taylor, \& Wu, 2012). The chi-square statistic, in particular, is very sensitive to minor variations in model fit, and therefore could lead researchers to reject invariance based on trivial differences in model parameters (Cheung \& Rensvold, 2002). Invariance tests can also sometimes lead to a result of partial invariance, where most, but not all, of the parameters tested will be equivalent across groups (Millsap \& Olivera-Aguilar, 2012). Again, whether or not the identified source of variation is important - beyond statistical significancedepends on the constructs, sample, and nature of variation. Thus, it is imperative to examine the magnitude and meaning of any potential differences in the model, rather than relying solely on statistical criteria.

Given the widespread use of the MEIM and the MIBI, the factor structure of scores generated by these measures needs to be ascertained across groups. It is also essential to ascertain the factor structure of the ERI instruments over time so that we know whether the hypothesized dimensionality of scores generated by these measures is consistent or discrepant across age periods. Such analyses can speak directly to the question of universal versus group-specific models of ERI. Adopting a rigorous approach to ERI instrumentation may yield information about which aspects are universal and which aspects are group specific. Findings from such research may help us to develop an expanded and more nuanced theory of ethnic identity development, as our measures - and how we use them-are critical for theory development (Greenwald, 2012; Knight \& Zerr, 2010). Of course, even the most rigorous and consistent tests will not tell us whether other identity processes or content domains not included in the MEIM or MIBI might be structured differently across groups. This idea reinforces an important point, that the construct (ERI) and the measure (MEIM/MIBI) cannot be thought of as interchangeable. 


\section{Empirically Measuring the Development of ERI}

A third issue concerns the ways in which ERI develops over time. Patterns of developmental change in ERI are only beginning to be understood, for a number of reasons. First, although some longitudinal studies of ERI have begun to appear in the literature in recent years (e.g., French, Seidman, Allen, \& Aber, 2006; Hughes, Way, \& Rivas-Drake, 2011; Kiang, Witkow, Baldelomar, \& Fuligni, 2010; Knight, Vargas-Chanes, et al., 2009; Pahl \& Way, 2006; Rivas-Drake \& Witherspoon, in press; Seaton, Yip, Morgan-Lopez, \& Sellers, 2012; Syed \& Azmitia, 2009; Umaña-Taylor et al., 2009), the study of ERI is still largely limited to cross-sectional studies during adolescence and emerging adulthood. In their metaanalysis of research on ethnic identity and wellbeing, Smith and Silva (2011) reported that more than $93 \%$ (172 of 184) of the studies they included were cross-sectional. This focus on the adolescent and emerging adult age periods may be a function of Erikson $(1950,1968)$ and Arnett (2000) designating these age periods as the time when the majority of identity development work takes place. Restricting the study of ERI largely to adolescents and emerging adults "assumes the theory" and does not allow us to test the extent to which greater degrees of ERI development activity occur in adolescence and emerging adulthood than during other age periods.

During adolescence, the advent of formal operational thought allows for consideration of hypothetical and alternative possibilities - and the availability of counterfactual thinking opens up the potential for identity exploration (Krettenauer, 2005). In longitudinal studies of ERI from childhood to adolescence and emerging adulthood, the availability of more advanced cognitive abilities over time may allowand perhaps dictate - changes in measurement approaches during the various age periods examined. What is needed is prospective longitudinal research on ERI, beginning in elementary school and continuing into adolescence and emerging adulthood. Such work is critical to establishing ERI as a developmental construct that emerges well before adolescence and continues to develop into the emerging adult years and beyond (see Bernal \& Knight, 1993, for a collection of reviews). Of course, measurement invariance analyses and multimethod-multitrait research designs would be necessary to ensure that the same construct was being assessed across the various developmental periods under study.

Measurement issues are especially important when conceptualizing studies that can advance and refine theory (Greenwald, 2012). For example, in longitudinal research, studies of developmental processes are predicated on the use of measures that are sufficiently reliable and sensitive to change over time. Measures with low reliability are likely to produce scores that vary randomly over time, which in turn compromises our ability to examine systematic developmental change (Little, 2013). Measures that are not sufficiently sensitive to developmental change are likely to produce scores that are more stable over time than are the true developmental processes under study. Rigorous research designs, including reliable and developmentally sensitive measures, are essential to advancing our understanding of how ERI develops over time.

\section{Future Directions: Four Key Challenges to ERI Development Research}

Addressing the overlap between ethnic and racial identity, as well as generating further insights into the three conceptual issues discussed above, will require some important methodological decisions. In our discussion of the three issues, we included methodological material where it was directly relevant to specific topics. In this section, we discuss more general methodological issues that are essential to address in the study of ERI. Given the reciprocal relation between theoretical and methodological issues (Greenwald, 2012), we explicitly attend to the ways in which the methodological advances we suggest are likely to inform the conceptualization of ERI. In particular, we focus on four key methodological challenges that face the field: (a) the need for more sophisticated longitudinal data analytic techniques to capture the dynamics and heterogeneity of development, (b) increased emphasis on sampling and retention, (c) inclusion of mixed-ethnic youth in ERI theory and research, and (d) broadening the range of research methods that are employed in the ERI literature. These challenges reflect core methodological issues that have the potential to broaden the inclusiveness of ERI research and bring greater attention to the heterogeneity of ERI process and content.

\section{Longitudinal Data Analytic Issues}

Addressing the confluence versus divergence between ethnic and racial identity, the overlap between processes and content domains, the group specificity versus generalizability of ERI models, and longitudinal trajectories of ERI processes and 
content domains, and other important research issues requires innovative, and often complex, longitudinal data analytic techniques (see Hedeker \& Gibbons, 2006, for an in-depth review of some of these methods). Because the issues that we raised above are interconnected, the analytic techniques that we suggest here can be used to examine one or more of these issues at a time. Furthermore, the various issues that we raised at the beginning of this article are not necessarily "either-or" questions. For example, issues of race and ethnicity may be more interrelated for some groups than for others, and the developmental trajectories of ERI components may depend, at least in part, on the context in which this development is occurring (UmañaTaylor, Benet-Martínez, et al., in press). This principle of within-group heterogeneity suggests that studies examining key issues in ERI-regardless of which specific issues they are examining-should use mixture modeling (Muthén, 2001), which extracts latent groups of participants with similar patterns on the variables of interest. We provide more details and examples of two of these approaches that have particular relevance to ERI development research: latent growth mixture modeling (LGMM) and latent transition analysis. We offer an important word of caution first: Because latent classes almost always involve some degree of imprecision, care should be taken when placing participants into their "most likely" classes and using class membership as an observed variable (e.g., in chi-square analyses, analyses of variance, or $t$ tests). Clark and Muthén (2011) suggest that it may not be appropriate to use class membership as an observed variable if the entropy (classification reliability) of the class solution is below .80 .

LGMM (Muthén \& Muthén, 2000), along with group-based trajectory modeling (GBTM; Nagin \& Odgers, 2010) extracts unobserved groups based on similar starting points and change trajectories. That is, LGMM and GBTM identify multiple trajectories of growth within the sample, rather than a single growth trajectory that is typical of multilevel modeling, for example. The differences between LGMM and GBTM are both conceptual and statistical. LGMM assumes that the different groups extracted in the analyses actually represent distinct populations, and therefore, variations around the fixed parameters within each class are allowed. In contrast, GBTM is considered a convenient method to divide a single population into potentially useful categories. Because there is no assumption that the groups represent distinct distributions, the variation in growth parameters within each class is fixed to zero (see Jung \& Wickrama, 2008; Nagin \& Odgers, 2010, for more details).

Huang and Stormshak (2011) applied LGMM to examine change in ethnic identity from sixth to ninth grades among an ethnically diverse sample of early adolescents. Their analysis identified six groups. The two largest groups both began with moderately high levels of ethnic identity, with one group remaining at those levels ( $28 \%$ of the sample) and another group increasing (45\%). The other four groups were all relatively small $(4 \%-10 \%)$, but were theoretically interesting. For example, one group started out very low and increased sharply, and another group started out very high and decreased sharply. These findings show both convergence and divergence with single-trajectory studies covering the same period. For example, French et al. (2006) found a linear increase in ethnic identity affirmation from sixth to ninth grades, which was similar to largest class found by Huang and Stormshak (2011). The advantage of LGMM and GBTM, however, lies in identifying the classes that do not follow the majority path. Identifying such groups can lead to important questions: Why do some youth's ERI pathways diverge at sixth grade, with some increasing and others remaining stable? Why do some youth decrease sharply over time? Using methods that identify the less common pathways raises questions such as these that have the potential to advance our theoretical understanding of ERI.

Latent transition analysis is ideally suited to test the developmental sequences posited within some ERI models, such as Phinney's model of ethnic identity statuses (Matsunaga, Hecht, Elek, \& Ndiaye, 2010; Seaton et al., 2012). Classification into the ethnic identity statuses can be accomplished through latent class analysis. Latent class analysis is a form of cluster mixture analysis where the clustering variables are assumed to be largely independent of one another (Köhn, Steinley, \& Brusco, 2010). The algorithm extracts heterogeneous groups of individuals based on their standing on a set of variables entered into the model. Thus, using exploration and commitment as input variables, latent class analysis can be used to classify individuals into one of the four ethnic identity statuses: achieved, moratorium, foreclosed, and diffused.

Stage-based theories postulate specific patterns of transitions that should, and should not, occur-and to the extent to which the empirically extracted transition probabilities match the theoretical expectations, support for the theory can be assumed (al-Owidha, Green, \& Kroger, 2009). Thus, once 
latent class solutions are extracted at each time point, latent transition analysis can be used to compute the probabilities of moving between or among specific sets of classes over time. For example, given that a person is in the diffused status at age 14, what is the likelihood of progressing to the moratorium status at age 16? Assuming that all of the statuses emerge empirically at both time points (this is not a necessary condition for latent transition analysis to be conducted), the probabilities of a diffused individual at age 14 transitioning to any of the statuses-including remaining in diffusion-at age 16 can be computed.

Seaton et al. (2012) used latent transition analysis in a three-wave study of ERI among African American adolescents. After identifying latent classes that approximated the four ERI statuses at each time point, they calculated the probabilities of transition from one class to another between time points. Their findings provided particularly interesting insights regarding the diffused status. Youth in the diffused status were most likely either to remain diffused or to move to foreclosure. However, some did move from diffused to achieved, and this movement was predicted by higher levels of parental racial socialization. Thus, latent transition analysis allowed for an understanding of the nature of movement between identity status and what predicts such movement-and represents a promising analytic method for ERI researchers who are interested in the status model.

One of the limitations of latent class and latent transition analyses, like any clustering procedure, is that the classes or clusters extracted are sample specific. In addition, it cannot necessarily be assumed that the categories extracted will correspond to the categories posited by one's theory. If the sample being used is not representative of the target population, then the groups extracted within the sample may not reflect the clusters or classes in the population. An important implication of this sample specificity is that the classes or clusters extracted must be mapped onto existing theory, replicated with a new sample, or both (Busseri, Sadava, Molnar, \& DeCourville, 2009). For example, ERI trajectory classes found with a sample of Mexican Americans in Los Angeles, or with a sample of Chinese Americans in San Francisco, might be replicated in a sample of Puerto Ricans in New York or in a sample of Vietnamese Americans in New Orleans. If a multisite or multiple-group longitudinal study is used, the multiple sites provide a built-in replication (cf. Luyckx, Klimstra, Schwartz, \& Duriez, 2013). Given the expenses involved in collecting longitudinal data, it may also make sense to combine data sets across samples to increase power (Cooper \& Koenka, 2012).

However, to the extent to which one's sample is sufficiently representative, the extent to which the categories (both in terms of how many categories emerge and in terms of the content of those categories) extracted from the component dimensions correspond to what would be theoretically expected can be construed as a test of the theory itself. A similar statement can be made regarding patterns of transitions across categories over time. If the categories extracted, or the patterns of movement between and among categories are not consistent with theoretical expectations, then the underlying ethnic or racial identity model might need to be questioned (al-Owidha et al., 2009).

Nevertheless, mixture modeling (where latent classes are created) has several advantages over traditional longitudinal models. One such advantage is its flexibility. For example, if endorsement of each stage has been measured continuously, as is the case with the CRIS (Vandiver et al., 2002), then LGMM or latent class growth analysis can be used to determine the extent to which over-time changes in endorsement of specific racial identity stages support the predictions advanced by the theory. Mixture modeling can also address important questions that do not necessarily require longitudinal data, such as the interrelation of process and content. The latent groups extracted through the analysis may or may not coincide with membership in specific ethnic or racial groups, which in itself represents an important research question. For example, the associations between ERI processes and content areas can be allowed to vary across latent groups, with the assumption that race and ethnicity may be more interwoven for some individuals, groups, and contexts than for others.

\section{Sampling and Retention}

\section{Sampling}

The vast majority of ERI research relies on convenience sampling. For example, even if one accepts the developmental rationale for designating adolescence and emerging adulthood as an important period for identity development, one must acknowledge that one specific subset of these age groups - college students from 4-year institutionsrepresents the vast majority of individuals who have been studied in the ERI literature. There are a number of psychosocial and socioeconomic differ- 
ences between college students and non-collegeattending emerging adults in a number of areas, including engagement in active identity exploration, assumption of adult roles, and financial resources (Halperin, 2001). With specific reference to ERI, ethnic minorities - especially African Americans, Latinos, and American Indians - are less likely to attend 4-year colleges compared to Whites and Asian Americans (National Center for Education Statistics, 2011). This suggests that the ethnic minority students enrolled in 4-year colleges and universities may be particularly nonrepresentative of their respective ethnic groups-for example, collegeattending Latino emerging adults may not represent the population of Latino emerging adults in general. Accordingly, the field would benefit from using more sophisticated sampling techniques.

Fundamental epidemiology holds that representative samples are required to support the most definitive statements about a population (Scheaffer, Mendenhall, Ott, \& Gerow, 2012). However, population-based research is expensive and time consuming. Not surprisingly, then, the majority of studies have sampled from a single high school (e.g., Pahl \& Way, 2006), university (e.g., RivasDrake, 2012; Schwartz \& Zamboanga, 2008), or community (e.g., Sellers, Copeland-Linder, Martin, \& Lewis, 2006; Umaña-Taylor, Zeiders, \& Updegraff, 2013). Syed et al. (2013) used a sample drawn from 30 U.S. colleges and universities, but the sample was not randomly selected. The amount of bias created by sampling only subsets of the population in these studies is not known.

However, there may also be important disadvantages to using population-based data sets. Many population-based data sets, such as the National Longitudinal Study of Adolescent Health, do not include validated measures of ERI-and therefore, population-based studies of ERI are difficult to conduct. Some authors (e.g., Marsiglia, Kulis, Hecht, \& Sills, 2004) have sampled all schools with certain characteristics (e.g., primarily Latino and low income), whereas some have used population-based data sets that included some ERI items (e.g., the National Epidemiologic Survey on Alcohol Related Conditions, Burnett-Zigler, Bohnert, \& Ilgen, 2013; the National Latino and Asian American Study, Yip, Gee, \& Takeuchi, 2008). Again, however, there is a trade-off that must be made. Collecting population-based data requires sampling individuals from the target ethnic group across a range of socioeconomic and residential contexts - and may require complex sampling strategies such as stratified or cluster sampling so that underrepresented segments of the target ethnic group are included in sufficient numbers for analysis. Data sets collected for public use, which generally have already addressed these sampling issues, often can accommodate only a few items assessing each construct. The psychometric rigor that is gained through use of complete measures may not be available when only a subset of items is used - or when items from several different instruments are used together. In both convenience and population-based sampling, then, there may be important compromises made. The precise effects of these compromises need to be systematically studied.

\section{Minimizing Attrition in Longitudinal Studies}

As noted above, addressing the debate issues that we have raised in this article requires the conduct of rigorous longitudinal research. This rigor refers not only to how participants are sampled, but also to how they are followed up over time. That is, not only do longitudinal research designs need to start with relatively representative samples of the ethnic or cultural minority populations of interest, but they also need to maintain these representative samples by minimizing attrition. Associations between observed attrition in these longitudinal studies and either (a) participant characteristics or (b) intercepts or slopes of the individual change trajectories in ERI suggest that the attrition may bias our understanding of the developmental issues under study (cf. Dumville, Torgerson, \& Hewitt, 2006). However, in cases where substantial attrition occurs, the longitudinal data collection procedures may offer a statistical way of estimating the impact of the attrition on the observed individual trajectories if sufficient data points have been obtained from individual participants prior to dropping out. If differential attrition is expected based on prior findings, it can be built into the research design and power analyses before data are collected (Roy, Bhaumik, Aryal, \& Gibbons, 2007). Even so, the goal of any longitudinal study should be to maintain retention rates that are as high as possible.

Knight, Roosa, et al. (2009) describe a number of strategies for minimizing attrition in longitudinal studies of ethnic minority populations. For example, it may be useful to employ the same study staff over time as a way of establishing rapport between study staff and participants, and to obtain contact information for friends or relatives who will know how to reach participants who have relocated or are otherwise unreachable. Assessments can be con- 
ducted in locations convenient to participantssuch as in their homes, their workplaces, or coffee shops-rather than asking them to come to a university or research center. Assessment materials and consent/assent forms must be made available in language that is accessible to participants, where "language" refers both to the native tongue that participants speak and to the specific vernacular and colloquialisms that are familiar to them. Even some participants who speak English as a first language (e.g., African Americans, Caribbean Islanders) may use a different form of English than the researchers do, and research materials must be phrased in ways that are comfortable for the study population. A similar scenario occurs with other languages, such as Spanish, that are spoken in many different countries and where regional dialects may cause some words to carry different meanings for different cultural groups. In some cases, words that are part of everyday conversation in one subgroup may be considered vulgar in other subgroups. Demonstrating respect and consideration for participants and their beliefs and traditions is essential for retaining them in the sample, and ultimately for providing the most rigorous evaluation of key issues in the ethnic and racial identity literatures - such as the overlap between process and content, the developmental trajectories of these processes and content areas, and the applicability of these processes and content areas across ethnic, racial, and cultural groups.

\section{ERI in Biracial and Multiracial Individuals}

Yet another key challenge for ERI theory and research involves how to apply theoretical models and research measures to individuals from multiple racial or ethnic backgrounds. Bracey et al. (2004), for example, found that biracial individuals appear to represent a separate group - distinct from individuals who claim only one racial background-in terms of the association between ethnic identity and selfesteem. Renn (2008) echoed this position, reviewing research suggesting that, as part of the process of developing a biracial identity, individuals from mixed racial backgrounds often eventually develop a "biracial" identity that is not reducible to the individual racial groups in which the person has ancestry. Brittian, Umaña-Taylor, and Derlan (2013) found that certain dimensions of ethnic identity were most important for biracial college students, depending on the racial composition of the university that they attended. For biracial individuals attending more diverse universities, ethnic identity resolution (having committed to a specific view of one's ethnic group, whether positive or negative) was protective against anxiety symptoms, whereas for biracial individuals attending less diverse universities, ethnic identity affirmation (viewing one's ethnic group positively) was promotive of self-esteem.

From a collective identity perspective, the rapidly increasing number of biracial and multiracial individuals - as well as the prominence of biracial and multiracial people such as Barack Obama and Tiger Woods - has permitted these individuals to identify with one another and with a superordinate biracial or multiracial group (see Ashmore et al., 2004, for a review of collective identity principles). Such identification may have different effects depending on the context in which biracial or multiracial people find themselves. In any case, however, biracial or multiracial people most often cannot be placed into one of the standard racial or ethnic groups (e.g., White, Black, Latino, Asian, Native American) - and the applicability of ERI models should be examined with biracial or multiracial individuals considered as a separate group.

\section{Use of Diverse Methodological Approaches}

Thus far, most of the measurement instruments that we have reviewed in this article are used to elicit self-reports of ethnic/racial identity. However, there are a number of limitations involved in selfreport measures, such as socially desirable or inattentive responding, misinterpretation of item content, and use of words or idioms that are not familiar to the target population (Holtgraves, 2004). Greater attention to developing non self-report measurement approaches vis-à-vis ERI is critical if we are to circumvent the limitations associated with the exclusive use of self-reports.

Some progress has already been made in this regard. Narrative or mixed-method approaches have been used fruitfully in recent ethnic identity research (Syed \& Azmitia, 2008), and experimental methods have been used to examine measurement equivalence of ethnic identity across language of assessment (Schwartz et al., in press). Some studies have used vignettes followed by questions about the beliefs, attitudes, or behaviors of the characters in the vignette (Cameron, Rutland, Brown, \& Douch, 2006; Yoo \& Lee, 2008). Using daily diary methods, Yip (2005) has used survey methods in new and interesting ways to understand ERI at different time scales. The convergence (or divergence) of data from multiple methods can facilitate a better understanding of the developmental nature of 
ethnic and racial identity by teasing apart potential confounds related to measurement limitations (cf. Campbell \& Fiske, 1959).

\section{Conclusion}

In this article, we have reviewed a number of key conceptual and methodological issues in ERI research. In many cases, methodological innovations and advances can be used to address important questions in the field, such as the overlap between ethnic and racial identity, the interplay between process and content, the group specificity of ERI models, and the developmental course of ERI. Self-report measures such as the MEIM, EIS, CRIS, and MIBI have facilitated great progress in establishing ERI as a construct worthy of scientific investigation. The expansion of ERI theory and research outside of the cultural studies community and into fields such as public health, political science, sociology, anthropology, and communication requires that we develop a common set of assumptions, terminology, and methodological approaches that will permit synthesis and comparison of ERI findings across disciplines. Advances in data analytic techniques, such as mixture modeling, have facilitated the conduct of innovative and important ERI studies that would not have been possible 10 or 15 years ago. It is our hope that the recommendations we provide in this article will promote further progress in our understanding of ERI and its implications for developmental outcomes across ethnic and racial groups.

\section{References}

al-Owidha, A., Green, K. E., \& Kroger, J. (2009). On the question of an identity status category order: Rasch model step and scale statistics used to identify category order. International Journal of Behavioral Development, 33, 88-96. doi:10.1177/0165025408100110

Arnett, J. J. (2000). Emerging adulthood: A theory of development from the late teens through the twenties. American Psychologist, 55, 469-480. doi:10.1037/0003-066X.55.5.469

Ashmore, R. D., Deaux, K., \& McLaughlin-Volpe, T. (2004). An organizing framework for collective identity: Articulation and significance of multidimensionality. Psychological Bulletin, 130, 80-114. doi:10.1037/ 0033-2909.130.1.80

Bernal, M. E., \& Knight, G. P. (Eds.). (1993). Ethnic identity formation and transmission among Latinos and other minorities. Albany: State University of New York Press.

Bowleg, L. (2008). When Black + Lesbian + Woman $\neq$ Black Lesbian Woman: The methodological challenges of qual- itative and quantitative intersectionality research. Sex Roles, 59, 312-325. doi:10.1007/s11199-008-9400-z

Bracey, J. R., Bámaca, M. Y., \& Umaña-Taylor, A. J. (2004). Examining ethnic identity and self-esteem among biracial and monoracial individuals. Journal of Youth and Adolescence, 33, 123-132. doi:10.1023/B:JOYO. 0000013424.93635 .68

Brewer, M. B. (2003). Optimal distinctiveness, social identity, and the self. In M. R. Leary \& J. P. Tangney (Eds.), Handbook of self and identity (pp. 480-491). New York, NY: Guilford Press.

Brittian, A., Umaña-Taylor, A. J., \& Derlan, C. (2013). An examination of biracial college youths' family ethnic socialization, ethnic identity, and adjustment: Do self-identification labels and university context matter? Cultural Diversity and Ethnic Minority Psychology, 19, 177-189. doi:10.1037/a0029438

Burnett-Zigler, I., Bohnert, K. N., \& Ilgen, M. A. (2013). Ethnic identity, acculturation and the prevalence of lifetime psychiatric disorders among Black, Hispanic, and Asian adults in the U.S. Journal of Psychiatric Research, 47, 56-63. doi:10.1016/j.jpsychires.2012.08.029

Busseri, M. A., Sadava, S., Molnar, D., \& DeCourville, N. (2009). A person-centered approach to subjective wellbeing. Journal of Happiness Studies, 10, 161-181. doi:10. 1007/s10902-007-9072-3

Cameron, L., Rutland, A., Brown, R., \& Douch, R. (2006). Changing children's intergroup attitudes toward refugees: Testing different models of extended contact. Child Development, 77, 1208-1219. doi:10.1111/j. 1467-8624.2006.00929.x

Campbell, D. T., \& Fiske, D. W. (1959). Convergent and discriminant validation by the multi-trait, multi-method matrix. Psychological Bulletin, 56, 81-105. doi:10.1037/ h0046016

Casey-Cannon, S. L., Coleman, H. L. K., Knudtson, L. F., \& Velazquez, C. (2011). Three ethnic and racial identity measures: Convergent and divergent validity for diverse adolescents. Identity, 11, 64-91. doi:10.1080/ 15283488.2011.540739

Cheryan, S., \& Monin, B. (2005). Where are you really from: Asian Americans and identity denial. Journal of Personality and Social Psychology, 89, 717-730. doi:10. 1037/0022-3514.89.5.717

Cheung, G. W., \& Rensvold, R. B. (2002). Evaluating goodness-of-fit indexes for testing measurement invariance. Structural Equation Modeling, 9, 233-255. doi:10. 1207/S15328007SEM0902_5

Clark, S. L., \& Muthén, B. (2011). Relating latent class analysis results to variables not included in the analysis. Retrieved from http://www.statmodel.com/download/relating lca.pdf

Cokley, K. (2007). Critical issues in the measurement of ethnic and racial identity: A referendum on the state of the field. Journal of Counseling Psychology, 54, 224-234. doi:10.1037/0022-0167.54.3.224

Cooper, H., \& Koenka, A. C. (2012). The overview of reviews: Unique challenges and opportunities when 
research syntheses are the principal elements of new integrative scholarship. American Psychologist, 67, 446462. doi:10.1037/a0027119

Cross, W. E., Jr. (1991). Shades of Black: Diversity in African-American identity. Philadelphia, PA: Temple University Press.

Cross, W. E., Jr., \& Strauss, L. (1998). The everyday functions of African American identity. In J. K. Swim \& C. Stangor (Eds.), Prejudice: The target's perspective (pp. 267-279). New York, NY: Academic Press.

Crutchfield, R. D., Fernandes, A., \& Martinez, J. (2010). Racial and ethnic disparity and criminal justice: How much is too much? Journal of Criminal Law and Criminology, 100, 903-932. doi:0091-4169/10/10003-0903

Dimitrov, D. M. (2010). Testing for factorial invariance in the context of construct validation. Measurement and Evaluation in Counseling and Development, 43, 121-149. doi:10.1177/0748175610373459

Dumville, J. C., Torgerson, D. J., \& Hewitt, C. E. (2006). Reporting attrition in randomised clinical trials. British Medical Journal, 332, 969-971. doi:10.1136/bmj.332.7547. 969

Erikson, E. H. (1950). Childhood and society. New York, NY: Norton.

Erikson, E. H. (1968). Identity: Youth and crisis. New York, NY: Norton.

French, S. E., Seidman, E., Allen, L., \& Aber, J. L. (2006). The development of ethnic identity during adolescence. Developmental Psychology, 42, 1-10. doi:10.1037/ 0012-1649.42.1.1

Gaskin, D. J., Headen, A. E., Jr., \& White-Means, S. I. (2005). Racial disparities in health and wealth: The effects of slavery and past discrimination. Review of Black Political Economy, 32, 95-110. doi:10.1007/ s12114-005-1007-9

Gjerde, P. F., \& Onishi, H. (2000). In search of theory: The study of ethnic groups in developmental psychology. Journal of Research on Adolescence, 10, 289-298. doi:10. 1207/SJRA1003_2

Gonzales-Backen, M. A., \& Umaña-Taylor, A. J. (2011). Examining the role of physical appearance in Latino adolescents' ethnic identity. Journal of Adolescence, 34, 151-162. doi:10.1016/j.adolescence.2010.01.002

Greenwald, A. G. (2012). There is nothing so theoretical as a good method. Perspectives on Psychological Science, 7, 99-108. doi:10.1177/1745691611434210

Halperin, S. (Ed.). (2001). The forgotten half revisited: American youth and young families, 1988-2008. Washington, DC: American Youth Policy Forum.

Hedeker, D., \& Gibbons, R. D. (2006). Longitudinal data analysis. New York, NY: Wiley.

Helms, J. E. (1990). Black and White racial identity: Theory, research, and practice. New York, NY: Greenwood Press.

Helms, J. E., \& Cook, D. A. (1999). Using race and culture in counseling and psychotherapy: Theory and process. Needham Heights, MA: Allyn \& Bacon.

Hitlin, S., Brown, J. S., \& Elder, G. H., Jr. (2007). Measuring Latinos: Racial versus ethnic classifications and self-understandings. Social Forces, 86, 587-611. doi:10. $1093 / \mathrm{sf} / 86.2 .587$

Holtgraves, T. (2004). Social desirability and self-reports: Testing models of socially desirable responding. Personality and Social Psychology Bulletin, 30, 161-172. doi:10. $1177 / 0146167203259930$

Huang, C. Y., \& Stormshak, E. A. (2011). A longitudinal examination of early adolescent ethnic identity trajectories. Cultural Diversity and Ethnic Minority Psychology, 17, 261-270. doi:10.1037/a0023882

Hughes, D., Way, N., \& Rivas-Drake, D. (2011). Stability and change in private and public ethnic regard among African American, Puerto Rican, Dominican, and Chinese American urban early adolescents. Journal of Research on Adolescence, 21, 861-870. doi:10.1111/j.1532-7795.2011. 00744.x

Johnson, T. M., Kurpius, S. E. R., Rayle, A. D., Arredondo, P., \& Tovar-Gamero, Z. G. (2005). The Multidimensional Inventory of Black Identity: Its use with Euro-American, Latino, and Native American undergraduates. Measurement and Evaluation in Counseling and Development, 38, 92-103.

Juang, L. P., Nguyen, H. H., \& Lin, Y. (2006). The ethnic identity, other-group attitudes, and psychosocial functioning of Asian American emerging adults from two contexts. Journal of Adolescent Research, 21, 542-568. doi:10.1177/0743558406291691

Jung, T., \& Wickrama, K. A. S. (2008). An introduction to latent class growth analysis and growth mixture modeling. Social and Personality Psychology Compass, 2, 302317. doi:10.1111/j.1751-9004.2007.00054.x

Kao, H. F., \& Travis, S. S. (2005). Effects of acculturation and social exchange on the expectations of filial piety among Hispanic/Latino parents of adult children. Nursing and Health Sciences, 7, 226-234. doi:10.1111/ j.1442-2018.2005.00241.x

Kiang, L., Witkow, M. R., Baldelomar, O. A., \& Fuligni, A. J. (2010). Change in ethnic identity across the high school years among adolescents with Latin American, Asian, and European backgrounds. Journal of Youth and Adolescence, 39, 683-693. doi:10.1007/s10964-009-9429-5

Knight, G. P., Roosa, M. W., \& Umaña-Taylor, A. J. (2009). Methodological challenges in studying ethnic minority or economically disadvantaged populations. Washington, DC: American Psychological Association.

Knight, G. P., Vargas-Chanes, D., Losoya, S. H., CotaRobles, S., Chassin, L., \& Lee, J. (2009). Acculturation and enculturation trajectories among Mexican-American adolescent offenders. Journal of Research on Adolescence, 19, 625-653. doi:10.1111/j.1532-7795.2009.00614.x

Knight, G. P., \& Zerr, A. A. (2010). Informed theory and measurement equivalence in child development research. Child Development Perspectives, 4, 25-30. doi:10.1111/j.1750-8606.2009.00112.x

Köhn, H.-F., Steinley, D., \& Brusco, M. J. (2010). The $p$-median model as a tool for clustering psychological data. Psychological Methods, 15, 87-95. doi:10.1037/ a0018535 
Krettenauer, T. (2005). The role of epistemic cognition in adolescent identity formation: Further evidence. Journal of Youth and Adolescence, 34, 185-198. doi:10.1007/ s10964-005-4300-9

Kroger, J., \& Marcia, J. E. (2011). The identity statuses: Origins, meanings, and interpretations. In S. J. Schwartz, K. Luyckx, \& V. L. Vignoles (Eds.), Handbook of identity theory and research (pp. 31-53). New York, NY: Springer.

Lee, R. M. (2005). Resilience against discrimination: Ethnic identity and other-group orientation as protective factors for Korean Americans. Journal of Counseling Psychology, 52, 36-44. doi:10.1037/0022-0167.52.1.36

Lee, R. M., \& Yoo, H.-C. (2004). Structure and measurement of ethnic identity for Asian American college students. Journal of Counseling Psychology, 51, 263-269. doi:10.1037/0022-0167.51.2.263

Lee, R. M., Yoon, E., \& Liu-Tom, H. T. (2006). Structure and measurement of acculturation/enculturation for Asian Americans using the ARSMA-II. Measurement and Evaluation in Counseling and Development, 39, 42-55.

Little, T. D. (2013). Longitudinal structural equation modeling. New York, NY: Guilford.

López, I. (2008). "But you don't look Puerto Rican": The moderating effect of ethnic identity on the relation between skin color and self-esteem among Puerto Rican women. Cultural Diversity and Ethnic Minority Psychology, 14, 102-108. doi:10.1037/1099-9809.14.2.102

Luhtanen, R., \& Crocker, J. (1992). A collective self-esteem scale: Self-evaluation of one's social identity. Personality and Social Psychology Bulletin, 18, 302-318. doi:10.1177/ 0146167292183006

Luyckx, K., Klimstra, T. A., Schwartz, S. J., \& Duriez, B. (2013). Personal identity in college and the work context: Developmental trajectories and psychosocial functioning. European Journal of Personality, 27, 222-237. doi:10.1002/per.1903

Marcia, J. E. (1966). Development and validation of ego identity status. Journal of Personality and Social Psychology, 3, 551-558. doi:10.1037/h0023281

Markstrom, C. (2011). Identity formation of American Indian adolescents: Local, national, and global considerations. Journal of Research on Adolescence, 21, 519-535. doi:10.1111/j.1532-7795.2010.00690.x

Marsiglia, F. F., Kulis, S., Hecht, M. L., \& Sills, S. (2004). Ethnicity and ethnic identity as predictors of drug norms and drug use among preadolescents in the U.S. Southwest. Substance Use and Misuse, 39, 1061-1094. doi:10.1081/JA-120038030

Matsunaga, M., Hecht, M., Elek, E., \& Ndiaye, K. (2010). Ethnic identity development and acculturation: A longitudinal analysis of Mexican-heritage youth in the Southwest United States. Journal of Cross-Cultural Psychology, 41, 410-427. doi:10.1177/0022022109359689

Millsap, R. E., \& Olivera-Aguilar, M. (2012). Investigating measurement invariance using confirmatory factor analysis. In R. H. Hoyle (Ed.), Handbook of structural equa- tion modeling (pp. 380-392). New York, NY: Guilford Press.

Moskowitz, G. B., Stone, J., \& Childs, A. (2012). Implicit stereotyping and medical decisions: Unconscious stereotype activation in practitioners' thoughts about African Americans. American Journal of Public Health, 102, 996-1001. doi:10.2105/AJPH.2011.300591

Mummendey, A., Klink, A., Mielke, R., Wenzel, M., \& Blanz, M. (1999). Socio-structural characteristics of intergroup relations and identity management strategies: Results from a field study in East Germany. European Journal of Social Psychology, 29, 259-285.

Muthén, B. O. (2001). Latent variable mixture modeling. In G. A. Marcoulines \& R. E. Schumacher (Eds.), New developments and techniques in structural equation modeling (pp. 1-33). Mahwah, NJ: Erlbaum.

Muthén, B. O., \& Muthén, L. K. (2000). Integrating person-centered and variable-centered analyses: Growth mixture modeling with latent trajectory classes. Alcoholism, 24, 882-891. doi:10.1111/j.1530-0277.2000.tb02070.x

Nagin, D. S., \& Odgers, C. L. (2010). Group-based trajectory modeling (nearly) two decades later. Journal of Quantitative Criminology, 26, 445-453. doi:10.1007/ s10940-010-9113-7

National Center for Education Statistics. (2011). Digest of education statistics, 2011. Retrieved from http://nces.ed. gov/programs/digest/d11/tables/dt11_237.asp

Pahl, K., \& Way, N. (2006). Longitudinal trajectories of ethnic identity among urban Black and Latino adolescents. Child Development, 77, 1403-1415. doi:10.1111/ j.1467-8624.2006.00943.x

Parham, T. A., \& Helms, J. E. (1985). Relation of racial identity attitudes to self-actualization and affective states of Black students. Journal of Counseling Psychology, 32, 431-440. doi:10.1037/0022-0167.32.3.431

Pegg, P. O., \& Plybon, L. E. (2005). Toward the theoretical measurement of ethnic identity. Journal of Early Adolescence, 25, 250-264. doi:10.1177/0272431604274175

Phinney, J. S. (1990). Ethnic identity in adolescents and adults: A review of research. Psychological Bulletin, 108, 499-514. doi:10.1037/0033-2909.108.3.499

Phinney, J. S. (1992). The Multigroup Ethnic Identity Measure: A new scale for use with diverse groups. Journal of Adolescent Research, 7, 156-176. doi:10.1177/ 074355489272003

Phinney, J. S. (1996). When we talk about American ethnic groups, what do we mean? American Psychologist, 51, 918-927. doi:10.1037/0003-066X.51.9.918

Phinney, J. S., \& Ong, A. D. (2007). Conceptualization and measurement of ethnic identity: Current status and future directions. Journal of Counseling Psychology, 54, 271-281. doi:10.1037/0022-0167.54.3.271

Ponterotto, J. G., Gretchen, D., Utsey, S. O., Stracuzzi, T., \& Saya, R., Jr. (2003). The Multigroup Ethnic Identity Measure (MEIM): Psychometric review and further validity testing. Educational and Psychological Measurement, 63, 502-515. doi:10.1177/0013164403063003010 
Portes, A., Fernández-Kelly, P., \& Haller, W. (2005). Segmented assimilation on the ground: The new second generation in early adulthood. Ethnic and Racial Studies, 28, 1000-1040. doi:10.1080/01419870500224117

Renn, K. A. (2008). Research on biracial and multiracial identity development: Overview and synthesis. New Directions for Student Services, 123, 13-21. doi:10.1002/ ss. 282

Rivas-Drake, D. (2012). Ethnic identity and adjustment: The mediating role of sense of community. Cultural Diversity and Ethnic Minority Psychology, 18, 210-215. doi: $10.1037 / \mathrm{a} 0027011$

Rivas-Drake, D., Hughes, D., \& Way, N. (2009). A preliminary analysis of associations among ethnic-racial socialization, ethnic discrimination, and ethnic identity among diverse urban sixth graders. Journal of Research on Adolescence, 19, 558-584. doi:10.1111/j.1532-7795. 2009.00607.x

Rivas-Drake, D., \& Witherspoon, D. (in press). Racial identity from adolescence to young adulthood: Does prior neighborhood experience matter? Child Development. Advance online publication. doi:10.1111/cdev. 12095

Roberts, R. E., Phinney, J. S., Masse, L. C., Chen, Y. R., Roberts, C. R., \& Romero, A. (1999). The structure of ethnic identity in young adolescents from diverse ethnocultural groups. Journal of Early Adolescence, 19, 301-322. doi:10.1177/0272431699019003001

Roy, A., Bhaumik, D. K., Aryal, S., \& Gibbons, R. D. (2007). Sample size determination for hierarchical longitudinal designs with differential attrition rates. Biometrics, 63, 699-707. doi:10.1111/j.1541-0420.2007.00769.x

Rumbaut, R. G. (2008). Reaping what you sow: Immigration, youth, and reactive ethnicity. Applied Developmental Science, 12, 108-111. doi:10.1080/10888690801997341

Scheaffer, R. L., Mendenhall, W., III, Ott, R. L., \& Gerow, K. G. (2012). Elementary survey sampling (7th ed.). Boston, MA: Brooks/Cole.

Schwartz, S. J., Benet-Martínez, V., Knight, G. P., Unger, J. B., Zamboanga, B. L., Des Rosiers, S. E., ... Szapocznik, J. (in press). Effects of language of assessment on the measurement of acculturation: Measurement equivalence and cultural frame switching. Psychological Assessment. Advance online publication. doi:10.1037/ a0034717

Schwartz, S. J., \& Zamboanga, B. L. (2008). Testing Berry's model of acculturation: A confirmatory latent class approach. Cultural Diversity and Ethnic Minority Psychology, 14, 275-285. doi:10.1037/a0012818

Schwartz, S. J., Zamboanga, B. L., Weisskirch, R. S., \& Rodriguez, L. (2009). The relationships of personal and ethnic identity exploration to indices of adaptive and maladaptive psychosocial functioning. International Journal of Behavioral Development, 33, 131-144. doi:10.1177/ 0165025408098018

Scottham, K. M., Sellers, R. M., \& Nguyen, H. X. (2008). A measure of racial identity in African American adolescents: The development of the Multidimensional
Inventory of Black Identity-Teen. Cultural Diversity and Ethnic Minority Psychology, 14, 297-306. doi:10.1037/ 1099-9809.14.4.297

Seaton, E. K., Yip, T., Morgan-Lopez, A., \& Sellers, R. M. (2012). Racial discrimination and racial socialization as predictors of African American adolescents' racial identity development using latent transition analysis. Developmental Psychology, 48, 448-458. doi:10.1037/a0025328

Seaton, E. K., Yip, T., \& Sellers, R. M. (2009). A longitudinal examination of racial identity and racial discrimination among African American adolescents. Child Development, 80, 406-417. doi:10.1111/j.1467-8624.2009.01268.x

Sellers, R. M., Copeland-Linder, N., Martin, P. P., \& Lewis, R. L. H. (2006). Racial identity matters: The relationship between racial discrimination and psychological functioning in African American adolescents. Journal of Research on Adolescence, 16, 187-216. doi:10.1111/ j.1532-7795.2006.00128.x

Sellers, R. M., Rowley, S. A., Chavous, T. M., Shelton, J. N., \& Smith, M. A. (1997). Multidimensional Inventory of Black Identity: Preliminary investigation of reliability and construct validity. Journal of Personality and Social Psychology, 73, 805-815. doi:10.1037/0022-3514.73.4.805

Sellers, R. M., Smith, M. A., Shelton, J. N., Rowley, S. A. J., \& Chavous, T. M. (1998). Multidimensional Model of Racial Identity: A reconceptualization of African American racial identity. Personality and Social Psychology Review, 2, 18-39. doi:10.1207/s15327957pspr0201_2

Smith, T. B., \& Silva, L. (2011). Ethnic identity and personal well-being of people of color: A meta-analysis. Journal of Counseling Psychology, 58, 42-60. doi:10.1037/ a0021528

Spears, R. (2011). Group identities: The social identity perspective. In S. J. Schwartz, K. Luyckx, \& V. L. Vignoles (Eds.), Handbook of identity theory and research (pp. 201-224). New York, NY: Springer.

Syed, M., \& Azmitia, M. (2008). A narrative approach to ethnic identity in emerging adulthood: Bringing life to the identity status model. Developmental Psychology, 44, 1012-1027. doi:10.1037/0012-1649.44.4.1012

Syed, M., \& Azmitia, M. (2009). Longitudinal trajectories of ethnic identity during the college years. Journal of Research on Adolescence, 19, 601-624. doi:10.1111/j. 1532-7795.2009.00609.x

Syed, M., \& Azmitia, M. (2010). Narrative and ethnic identity exploration: A longitudinal account of emerging adults' ethnicity-related experiences. Developmental Psychology, 46, 208-219. doi:10.1037/a0017825

Syed, M., Walker, L. H. M., Lee, R. M., Umaña-Taylor, A. J., Zamboanga, B. L., Schwartz, S. J., ... Huynh, Q.-L. (2013). A two-factor model of ethnic identity exploration: Implications for identity coherence and well-being. Cultural Diversity and Ethnic Minority Psychology, 19, 143-154. doi:10.1037/a0030564

Tajfel, H., \& Turner, J. C. (1986). The social identity theory of intergroup behavior. In S. Worchel \& W. G. Austin (Eds.), The psychology of intergroup behavior (pp. 7-24). Chicago, IL: Nelson Hall. 
Teo, T. (2009). Psychology without Caucasians. Canadian Psychology, 50, 91-97. doi:10.1037/a0014393

Tomarken, A. J., \& Waller, N. G. (2005). Structural equation modeling: Strengths, limitations, and misconceptions. Annual Review of Clinical Psychology, 1, 31-65. doi:10.1146/annurev.clinpsy.1.102803.144239

Turner, J. C., Hogg, M. A., Oakes, P. J., Reicher, S. D., \& Wetherell, M. S. (1987). Rediscovering the social group: A self-categorization theory. Oxford, UK: Blackwell.

Umaña-Taylor, A. J. (2011). Ethnic identity. In S. J. Schwartz, K. Luyckx, \& V. L. Vignoles (Eds.), Handbook of identity theory and research (pp. 791-807). New York, NY: Springer.

Umaña-Taylor, A. J., Gonzales-Backen, M. A., \& Guimond, A. B. (2009). Latino adolescents' ethnic identity: Is there a developmental progression and does growth in ethnic identity predict growth in self-esteem? Child Development, 80, 391-405. doi:10.1111/j.1467-8624.2009.01267.x

Umaña-Taylor, A. J., O’Donnell, M., Knight, G. P., Roosa, M. W., Berkel, C., \& Nair, R. (in press). Mexican-origin early adolescents' ethnic socialization, ethnic identity, and psychosocial functioning. The Counseling Psychologist. Advance online publication. doi:10.1177/ 0011000013477903

Umaña-Taylor, A. J., Quintana, S. M., Lee, R. M., Cross, W. E., Jr., Rivas-Drake, D., Schwartz, S. J., . . Ethnic and Racial Identity in the 21st Century Study Group. (2014). Ethnic and racial identity during adolescence and into young adulthood: An integrated conceptualization. Child Development, 85, 21-39.

Umaña-Taylor, A. J., Yazedjian, A., \& Bámaca-Gómez, M. Y. (2004). Developing the Ethnic Identity Scale using Eriksonian and social identity perspectives. Identity, 4, 9-38. doi:10.1207/S1532706XID0401_2

Umaña-Taylor, A. J., Zeiders, K. H., \& Updegraff, K. A. (2013). Family ethnic socialization and ethnic identity: A family-driven, youth-driven, or reciprocal process? Journal of Family Psychology, 27, 137-146. doi:10.1037/ a0031105

Vandiver, B. J., Cross, W. E., Jr., Worrell, F. C., \& FhagenSmith, P. (2002). Validating the Cross Racial Identity Scale. Journal of Counseling Psychology, 49, 71-85. doi:10. 1037/0022-0167.49.1.71

Waldinger, R. D., \& Feliciano, F. (2004). Will the new second-generation assimilate downward? Segmented assimilation re-assessed. Ethnic and Racial Studies, 27, 376-402. doi:10.1080/01491987042000189196

Waters, M. C. (1999). Black identities: West Indian immigrant dreams and American realities. Cambridge, MA: Harvard University Press.
Way, N., Santos, C., Niwa, E. Y., \& Kim-Gervey, C. (2008). To be or not to be: An exploration of ethnic identity development in context. New Directions for Child and Adolescent Development, 120, 61-79. doi:10. $1002 /$ cd. 216

West, S. G., Taylor, A. B., \& Wu, W. (2012). Model fit and model selection in structural equation modeling. In R. H. Hoyle (Ed.), Handbook of structural equation modeling (pp. 209-231). New York, NY: Guilford.

Worrell, F. C., \& Gardner-Kitt, D. L. (2006). The relationship between racial and ethnic identity in Black adolescents: The Cross Racial Identity Scale and the Multi-Group Ethnic Identity Measure. Identity, 6, 293-315. doi:10.1207/ s1532706xid0604_1

Yip, T. (2005). Sources of situational variation in ethnic identity and psychological well-being: A Palm Pilot study of Chinese American students. Personality and Social Psychology Bulletin, 31, 1603-1616. doi:10.1177/ 0146167205277094

Yip, T., Gee, G. C., \& Takeuchi, D. T. (2008). Racial discrimination and psychological distress: The impact of ethnic identity and age among immigrant and United States-born Asian adults. Developmental Psychology, 44, 787-800. doi:10.1037/0012-1649.44.3.787

Yip, T., Seaton, E. K., \& Sellers, R. M. (2006). African American racial identity across the lifespan: Identity status, identity content, and depressive symptoms. Child Development, 77, 1504-1517. doi:10.1111/j. 1467-8624.2006.00950.x

Yip, T., Seaton, E. K., \& Sellers, R. M. (2010). Interracial and intraracial contact, school-level diversity, and change in racial identity status among African American adolescents. Child Development, 77, 1504-1517. doi:10.1111/j.1467-8624.2010.01483.x

Yoo, H.-C., Burrola, K. S., \& Steger, M. F. (2010). A preliminary report on a new measure: Internalization of the Model Minority Myth Measure (M\&Ms) and its psychological correlates among Asian American college students. Journal of Counseling Psychology, 57, 114-127. doi: $10.1037 / \mathrm{a} 0017871$

Yoo, H.-C., \& Lee, R. M. (2008). Does ethic identity protect or exacerbate the effects of frequent racial discrimination on situational well-being of Asian Americans? Journal of Counseling Psychology, 55, 63-74. doi:10.1037/ 0022-0167.55.1.63

Yoon, E. (2011). Measuring ethnic identity in the Ethnic Identity Scale and the Multigroup Ethnic Identity Measure-Revised. Cultural Diversity and Ethnic Minority Psychology, 17, 144-155. doi:10.1037/a0023361 